\title{
Fluoride gels reduce caries incidence by 20 percent
}

\author{
Van Rijkom HM, Truin G J, Van't HofM A. A meta-analysis of clinical studies on the caries inhibiting effect of \\ fluoride gel treatment. Caries Res. 1998; 32: 83-92.
}

\begin{abstract}
Objectives To assess the overall caries inhibiting effect of clinical fluoride gel treatment studies and to explore factors potentially modifying an effect.
\end{abstract}

Data Sources A Medline search was conducted between 1965 and 1995 using the key words 'fluoride', 'gel' and '(dental) caries' for English and German language studies.

\section{Study selection Papers not related to coronal caries were excluded leaving 40 for consideration. Only randomised controlled trials in permanent teeth of children 6-15 with caries incidence data at surface level, with effect evaluation at the end of the application period were included leaving 19 papers.}

Data extraction and synthesis Some standard deviation and standard errors were missing for 5 studies: these were estimated using. The prevented fraction and the number needed to treat was calculated.

Results The prevented fraction for the overall group is 20\% (95\% CI 19.3-21.5\%). The tables show the numbers needed to treat

\begin{tabular}{|c|c|c|c|}
\hline & \multicolumn{3}{|c|}{ Prevented fraction } \\
\hline & Studies & Mean & $95 \% \mathrm{Cl}$ \\
\hline $\begin{array}{l}\text { Overall } \\
\text { Trays } \\
\text { Brushes }\end{array}$ & $\begin{array}{r}19 \\
12 \\
7\end{array}$ & $\begin{array}{l}20.3 \\
20.2 \\
20.4\end{array}$ & $\begin{array}{l}19.8-21.5 \\
19.1-21.5 \\
19.5-21.5\end{array}$ \\
\hline $\begin{array}{c}\text { DMFS incremen } \\
\text { per annum }\end{array}$ & $\begin{array}{l}{ }^{\dagger} \text { Overall } \\
\text { NNT }\{95 \% \text { Cl })\end{array}$ & $\begin{array}{l}\text { Brushes } \\
\text { NNT } 195 \% \mathrm{Cl}\}\end{array}$ & $\begin{array}{c}\text { Trays } \\
\text { NNT } 195 \% \text { Cl| }\end{array}$ \\
\hline $\begin{array}{l}0.25 \\
1 \\
2\end{array}$ & $\begin{array}{l}20(19-21) \\
5(5) \\
3(2-3)\end{array}$ & $\begin{array}{l}20(19-21) \\
5(5) \\
3(2-3)\end{array}$ & $\begin{array}{c}20(19-21) \\
5(5) \\
3(2-3)\end{array}$ \\
\hline
\end{tabular}

(NNT) and preventive fraction for trays and brushes separately, together with the overall NNT and NNTs at different levels of disease.

Conclusions The overall prevented fraction of fluoride gel treatments was found to be $20 \%$.

Address for reprints: Hans van Rijkom, 117 College of Dental Science, University of Nijmegan, PO Box 9101.NL, $-6500 \mathrm{HB}$ Nljmegen, The Netherlands.

\section{Commentary}

Despite some limitations in the search strategy of this meta-analysis, the authors clearly assessed the rigour of the included studies. Nineteen studies met the inclusion criteria, producing a pooled preventive fraction (PF) or percent reduction in caries incidence of $20 \%$. This reduction falls within narrow $95 \%$ confidence intervals and was consistent with earlier summaries using traditional (non-statistical) methods. This translates to a number needed to treat (NNT) of 3 to avoid 1 DMFS in a population with a caries incidence of 2 DMFS. For children with a lower caries incidence $(0.25 \mathrm{DMFS} / \mathrm{yr})$ the NNT would rise to 20 ).

The authors tested the assumption of a constant relative treatment effect by stratifying every trial according to baseline risk of the study population. While $\mathrm{PF}$ tended to increase as trials involved children with 'high' and 'very high' DMFS scores, regression analysis did not show any significant influence on the prevented fractions of baseline caries prevalence.

Using NNT, the paper compared resources expended to prevent or treat one DMFS. It appears that in the Netherlands, cost-effectiveness analysis would favour a strategy of waiting and restoring decayed teeth over a strategy of prevention with fluoride gels. Nevertheless, benefits of fluoride treatment may be greater than those revealed in the traditional DMF index, e.g., patients may prefer, and be willing to pay for, a sound rather than a restored tooth. Thus even though the cost differential between the two strategies was large, the study was not a full economic appraisal, and conclusions need to be stated with that caveat.

Thus, the PF estimated from earlier reviews and this estimate derived from a formal meta-analysis, demonstrate that fluoride gels are efficacious in reducing the occurrence of new surface dentinal caries. However, this study, by presenting the NNT, allows clinicians and patients to more easily interpret the relative efficiency of fluoride gels in the context of a continued downward trend of caries incidence and widespread use of alternate sources of fluorides.

As to the impact of this study, many dentists and patients will probably consider that the estimates in terms of potential future caries reductions (PF) represent an important health benefit. As stated previously, some patients, given the information in the form of NNTs, may still prefer preventive rather than restorative treatment. However NNTs reinforce the rational for targeting preventive care to high-risk patients. Clinicians, with the NNTs provided by this meta-analysis, now have another method to communicate the potential benefits of their care for patient/clinician decision-making.

Herenia P. Lawrence,

James L. Leake

University of Toronto, Toronto,

Canada 